\title{
Toll-like receptors 1-9 are elevated in livers with fructose-induced hepatic steatosis
}

\author{
Sabine Wagnerberger, Astrid Spruss, Giridhar Kanuri, Valentina Volynets, Carolin Stahl, \\ Stephan C. Bischoff and Ina Bergheim* \\ Department of Nutritional Medicine, University of Hohenheim (180 a), Fruwirthstrasse 12, 70599 Stuttgart, \\ Germany
}

(Submitted 10 January 2011 - Final revision received 2 August 2011 - Accepted 5 August 2011 - First published online 10 October 2011)

\section{Abstract}

Studies in animals and human subjects indicate that gut-derived bacterial endotoxins may play a critical role in the development of nonalcoholic fatty liver disease (NAFLD). In the present study, we investigated if the liver is also sensitised by other microbial components during the onset of fructose-induced steatosis in a mouse model. C57BL/6 mice were either fed with $30 \%$ fructose solution or tap water (control) with or without antibiotics for 8 weeks. Expression of toll-like receptors (TLR)1-9, TNF- $\alpha$, inducible NO synthase (iNOS), myeloid differentiation factor 88 (MyD88) and number of F4/80 positive cells in the liver were assessed. Occludin protein, DNA of microbiota in the small and large intestine and retinol binding protein 4 (RBP4) in plasma were analysed using Western blot, DNA fingerprinting and ELISA, respectively. F4/80 positive cells were determined by immunohistochemistry. The accumulation of TAG found in the livers of fructose-fed mice was associated with a significant induction of TLR 1-4 and 6-8. Plasma RBP4 concentration and hepatic mRNA expression levels of TNF- $\alpha$, iNOS, MyD88 and number of F4/80 positive cells of fructose-fed animals were significantly higher than those of controls; however, these effects of fructose were attenuated in antibiotic-treated mice. Whereas protein concentration of occludin was lower in the duodenum of fructose-treated mice, no systematic alterations of microbiota were found in this part of the intestine. Taken together, these data support the hypothesis that (1) an increased intestinal translocation of microbial components and (2) an increased number of $\mathrm{F} 4 / 80$ positive cells and induction of several TLR and dependent pathways (e.g. MyD88 and iNOS) may be involved in the onset of fructose-induced NAFLD.

\section{Key words: Toll-like receptor: Fructose: Non-alcoholic fatty liver disease: Occludin}

During the last three decades, non-alcoholic fatty liver disease (NAFLD) has advanced to be among the most common liver diseases worldwide. NAFLD usually develops in a setting of obesity and insulin resistance ${ }^{(1)}$ and comprises a continuum of diseases ranging from simple steatosis to steatohepatitis and cirrhosis. Herein, steatosis is the earliest and most common type of NAFLD and has long been thought to be a relatively benign state of liver injury. However, in more recent years, it became clear that fatty livers are more vulnerable to injury from various causes ${ }^{(2)}$ and can progress to steatohepatitis, increasing the probability of further liver-related morbidity and mortality ${ }^{(3)}$. Despite the fact that NAFLD is a common cause of chronic liver disease ${ }^{(4,5)}$, the optimal treatment for NAFLD and strategies to prevent the onset and progression of NAFLD have not yet been established. A better understanding of the mechanisms underlying the development of the early stages of NAFLD (e.g. steatosis) might add not only to therapies preventing steatosis but may also add to the development of strategies to prevent the progression of the disease.
Due to its anatomical links to the gut, the liver is constantly exposed to gut-derived bacterial products and functions at first line of defence. Kupffer cells, the resident macrophages of the liver, have been shown to be able to efficiently take up endotoxin and phagocytose bacteria carried through the portal vein, thereby playing a major role in the protection against systemic bacterial infection (for an overview, see Mencin et $\left.a l .{ }^{(6)}\right)$. Through pattern recognition receptors (e.g. toll-like receptors (TLR)), immune cells like Kupffer cells recognise molecular patterns, which are expressed in pathogens $^{(7)}$. In the healthy liver, mRNA expression of TLR such as TLR1, TLR2, TLR4, TLR6, TLR7, TLR8, TLR9 and TLR10 is low in comparison to other organs. It has been proposed that the low expression of TLR signalling molecules may contribute to the high tolerance of the liver to TLR ligands from the intestinal microbiota to which the liver is constantly exposed. In recent years, the specific ligands of these TLR have begun to be better characterised: thus, TLR2 is essential for the recognition of microbial lipopeptides and TLR1 and

Abbreviations: AB, treatment with antibiotics (polymyxin B and neomycin); C, water control; F, 30\% fructose solution; MyD88, myeloid differentiation factor 88; NAFLD, non-alcoholic fatty liver disease; rDNA, ribosomal DNA; TLR, toll-like receptor.

*Corresponding author: I. Bergheim, fax +49711 459 24343, email ina.bergheim@uni-hohenheim.de 
6 combined with TLR2 distinguish the subtle differences between triacyl- and diacyllipopeptides ${ }^{(8)}$. TLR3 is involved in the recognition of viral double-stranded RNA and TLR5 recognises bacterial flagellin ${ }^{(9,10)}$. TLR4 recognises lipopolysaccharides from Gram-negative bacteria ${ }^{(11)}$. TLR7 and TLR8 bind viral single-stranded RNA ${ }^{(12)}$. Lastly, TLR9 recognises bacterial and viral DNA-containing unmethylated cytidine phosphate guanosine $(\mathrm{CpG})$ motifs $^{(13)}$. The interaction of TLR with their ligands results in an activation of myeloid differentiation factor 88 (MyD88) and/or interferon regulatory factor 3 and 7 and subsequently through the activation of nuclear transcription factors to the release of numerous proinflammatory mediators such as $\mathrm{TNF} \alpha$, which in turn can induce liver injury and fibrosis (for overviews, see Mencin et al. ${ }^{(6)}$, Nagata et al. ${ }^{(14)}$ and Nagy $\left.{ }^{(15)}\right)$. However, whether the liver is also sensitised by other microbial components besides bacterial endotoxin derived from Gram-negative bacteria during the onset of fructose-induced NAFLD has not yet been determined.

Results of recent human studies suggest that besides a diet rich in fat, the intake of sugar, and herein particularly fructose, may be a risk factor for the development of steatosis (for an overview, see Spruss \& Bergheim ${ }^{(16)}$ ), but may be even more so for the progression of NAFLD to later stages of the disease (e.g. fibrosis) ${ }^{(17)}$. The hypothesis that the intake of carbohydrates, and particularly of the mono- and disaccharides fructose and sucrose, might play a critical role in the development of NAFLD is also supported by a number of studies performed in animals ${ }^{(18-21)}$. Indeed, in these studies performed in rodents, it was shown that an increased consumption of fructose (e.g. up to $60 \%$ of daily energy derived from fructose) may result in increased lipid accumulation in the liver, elevated plasma TAG levels and oxidative stress $^{(18-21)}$. It was further shown that chronic intake of fructose may lead to insulin resistance. Indeed, markers for insulin resistance like retinol binding protein 4 and TNF $\alpha$ were found to be markedly higher in plasma of fructose-fed mice than in controls ${ }^{(22)}$. Furthermore, we recently showed that the development of fructose-induced hepatic steatosis is associated with a partial loss of the tight junction protein occludin in the upper parts of the small intestine and an increased translocation of bacterial endotoxin ${ }^{(23)}$. Similar alterations were not found in mice exposed to a $30 \%$ glucose solution $^{(20,23)}$. In these studies, we further found that the concomitant treatment of mice with antibiotics or the loss of the endotoxin receptor, TLR- 4 , both markedly attenuated the development of fructose-induced hepatic steatosis ${ }^{(20,22)}$. In fructose-fed TLR-4-mutant $(\mathrm{C} 3 \mathrm{H} / \mathrm{HeJ})$ mice, hepatic steatosis was significantly reduced in comparison to fructose-fed wild-type mice, even though portal endotoxin levels were similar in both groups ${ }^{(22)}$. This protective effect of the loss of TLR- 4 was accompanied by decreased lipid-peroxidation, MyD88 and TNF $\alpha$ levels ${ }^{(22)}$

However, whether alterations of the intestinal microbiota or direct effects of fructose on the intestinal barrier are involved in the increased translocation of bacterial endotoxin and if other TLR besides TLR 4 may also be involved in the onset of fructose-induced NAFLD have not yet been clarified.
Starting from this background, the aim of the present study was to determine (1) if the chronic intake of fructose results in alterations of intestinal microbiota and (2) if the abundance of other TLR in the liver besides TLR4 is also affected by chronic exposure to fructose.

\section{Materials and methods}

\section{Animals and treatments}

C57BL/6J-mice (6 to 8 weeks old) (Janvier S.A.S., Le Genest Saint Isle, France) were housed in a pathogen-free barrier facility accredited by the Association for Assessment and Accreditation of Laboratory Animal Care. All procedures were approved by the local Institutional Animal Care and Use Committee. Additionally to normal chow, C57BL/6J mice were either fed with $30 \%$ fructose solution (F) or with plain tap water (control; C) for 8 weeks. In this model, total energy intake was higher in fructose-fed mice compared to water-fed controls $(P<0.05$ as tested with Mann-Whitney $U$ test; fructose-fed mice: about 17\%); however, weight gain of control animals and mice fed with fructose did not differ, as absolute weight gain varied considerably between groups $^{(20)}$. Some fructose-fed animals $(\mathrm{F}+\mathrm{AB})$ as well as control mice $(\mathrm{C}+\mathrm{AB})$ were additionally treated with a combination of the two antibiotics polymyxin B $(92 \mathrm{mg} / \mathrm{kg}$ body weight) and neomycin ( $216 \mathrm{mg} / \mathrm{kg}$ body weight). At the time of killing, portions of liver tissue were frozen immediately in liquid $\mathrm{N}_{2}$ and stored at $-80^{\circ} \mathrm{C}$, while others were frozenfixed in Tissue Tek $^{\circledR}$ O.C.T. ${ }^{\text {тм }}$ compound (Sakura Finetek Europe, Alphen aan den Rijn, The Netherlands) for subsequent sectioning and mounting on microscope slides. Data representing liver steatosis (e.g. liver: body weight ratio, hepatic lipid accumulation and hepatic TAG concentration) have been published before ${ }^{(20)}$ and are not further detailed in the present study.

\section{RNA isolation and real-time RT-PCR}

Total RNA was extracted from liver tissue samples by a guanidium thiocyanate-based method (peqGOLD TriFast; Peqlab, Erlangen, Germany). RNA concentrations were determined spectrophotometrically and after a DNase digestion step (Fermentas, St Leon-Rot, Germany), $1 \mu \mathrm{g}$ total RNA was reverse transcribed using an Moloney murine leukaemia virus (MuLV) RT and oligo (dT) primers (Fermentas). Primers for TLR1-9, TNF- $\alpha$, iNOS, MyD88, F4/80 and $\beta$-actin were designed using Primer 3 (Whitehead Institute for Biomedical Research, Cambridge, MA, USA; Table 1). Sybr ${ }^{\circledR}$ Green Universal PCR Master Mix (Applied Biosystems, Darmstadt, Germany) was used to prepare the PCR mix. Primers were added to a final concentration of $300 \mathrm{~nm}$. The amplification reactions were carried out in an iCycler (Bio-Rad Laboratories, Munich, Germany) with an initial hold step $\left(95^{\circ} \mathrm{C}\right.$ for $3 \mathrm{~min}$ ) and fifty cycles of a three-step PCR $\left(95^{\circ} \mathrm{C}\right.$ for $15 \mathrm{~s}, 60^{\circ} \mathrm{C}$ for $30 \mathrm{~s}, 72^{\circ} \mathrm{C}$ for $30 \mathrm{~s}$ ). The fluorescence intensity of each sample was measured at each temperature change to monitor amplification of the target gene. The comparative $C_{\mathrm{T}}$ method 
Table 1. Primers used for real-time RT-PCR detection of toll-like receptor (TLR)1-9, TNF- $\alpha$, inducible NO synthase (iNOS), myeloid differentiation factor 88 (MyD88) and $\beta$-actin

\begin{tabular}{lll}
\hline & Forward $\left(5^{\prime}-3^{\prime}\right)$ & Reverse $\left(5^{\prime}-3^{\prime}\right)$ \\
\hline TLR 1 & CGC CTG GAC CCA GAG TTT GT & CGC ACC CAG GAA GGT CAG TT \\
TLR 2 & CTC CAC AAG CGG GAC TTC GT & GGG CTC CAG CAA AAC AAG GA \\
TLR 3 & CGC CCT CCT CTT GAA CAA CG & GGA ACC GTT GCC GAC ATC AT \\
TLR 4 & AGC CAT TGC TGC CAA CAT CA & GCT GCC TCA GCA GGG ACT TC \\
TLR 5 & AGC CTC CGC CTC CAT TCT TC & TCA CGC CTC TGA AGG GGT TC \\
TLR 6 & CCC AAA GAC CTG CCA CCA AG & CGC CAT AGG GCA GCA AGA GA \\
TLR 7 & CCC ATG TGA TCG TGG ACT GC & CAT TGG CTT TGG ACC CCA GT \\
TLR 8 & TCT CCT CCA TGC CCC ACA TT & TGC CAT TGT GGC TCA GGT TT \\
TLR 9 & ATC ACC ACT GTG CCC CGA CT & GAG ATT GCT CAG GCC CAG GA \\
TNF- $\alpha$ & CCA GGC GGT GCC TAT GTC TC & CAG CCA CTC CAG CTG CTC CT \\
iNOS & CAG CTG GGC TGT ACA AAC CTT & CAT TGG AAG TGA AGC GTT TCG \\
MyD88 & CAA AAG TGG GGT GCC TTT GC & AAA TCC ACA GTG CCC CCA GA \\
F4/80 & TGG CTG CCT CCC TGA CTT TC & CAA GAT CCC TGC CCT GCA CT \\
$\beta-A c t i n$ & GGC TCC TAG CAC CAT GAA & AGC CAC CGA TCC ACA CAG A \\
\hline
\end{tabular}

was used to determine the amount of target, normalised to an endogenous reference $(\beta$-actin) and relative to a calibrator $\left(2^{-\Delta \Delta C_{t}}\right)$. The purity of PCR products was verified by melting curves and gel electrophoresis.

\section{Immunostaining of F4/80 in liver tissue}

To determine $\mathrm{F} 4 / 80$ positive cells, a marker of macrophages, paraffin-embedded liver sections $(5 \mu \mathrm{m})$ were deparaffinased and rehydrated in ethanol solutions with decreasing concentrations. Liver tissue was stained for $\mathrm{F} 4 / 80$ by blocking slides with $10 \%$ bovine serum albumin in PBS with $0 \cdot 1 \%$ Tween 20 (PBST; Carl Roth GmbH \& Co. KG, Karlsruhe, Germany) for $30 \mathrm{~min}$, washing with PBST and an overnight incubation with a monoclonal primary antibody solution (Abcam, Cambridge, UK) in a humidified chamber at $4{ }^{\circ} \mathrm{C}$. Liver sections were washed and incubated with a biotinylated rabbit polyclonal secondary antibody to rat IgG (Abcam). Peroxidase was linked by incubating slides with streptavidine-horse radish peroxidase (HRP) (DAKO, Hamburg, Germany). To detect specific binding of $\mathrm{F} 4 / 80$ antibody tissue sections were incubated with diaminobenzidine (DAKO). The numbers of F4/80 positive cells were counted. Data from eight fields (630x, Axio Vert 200M; Zeiss, Jena, Germany) of each tissue section were used to determine means.

\section{Retinol binding protein 4 determination}

Plasma retinol binding protein 4 concentrations were determined using a commercially available ELISA (Alpco Diagnostics, Salem, NH, USA) according to the manufacturer's instructions.

\section{Western blot}

To obtain samples of duodenal, ileal and colonic protein, snap-frozen samples of tissue obtained from the duodenum, ileum and colon were homogenised in peqGOLD TriFast (Peqlab, Erlangen, Germany) and protein was isolated according to the manufacturer's instructions. Protein lysates $(10-30 \mu \mathrm{g}$ protein/well) were separated in a
$10 \%$ SDS-polyacrylamide gel and transferred to Hybond ${ }^{\mathrm{TM}}-\mathrm{P}$ polyvinylidene difluoride membranes (Amershan Biosciences, Freiburg, Germany). The resulting blots were then probed with antibodies against occludin (Zymed, San Francisco, CA, USA) and bands were visualised using a Super Signal Western Dura kit (Pierce; Perbio Science, Rockford, IL, USA). To ensure equal loading, all blots were stained with Ponceau red; signals of occludin were normalised to $\beta$-actin, which was detected using a commercially available antibody (New England Biolabs, Frankfurt, Germany). Protein bands were analysed densitometrically using Fluorchem Software (Alpha Innotech, San Leandro, CA, USA).

\section{Fingerprinting of bacterial DNA}

Total bacterial DNA was isolated from the duodenum, ileum and colon using a commercially available kit (QIAamp DNA Stool Mini Kit; Qiagen, Hilden, Germany). 16S ribosomal DNA (rDNA) was amplified using PCR with primers (16S 27F: 5'-AGA GTT TGA TCM TGG CTC AG-3'; 16S 1492R: 5'-TAC GGY TAC CTT GTT ACG ACT T-3'), which are specific for bacterial $16 \mathrm{~S}$ rDNA sequences. PCR was performed by using a polymerase master-mix (F-508; Finnzymes, Espoo, Finland). The amplification reactions were carried out in a thermocycler (Bio-Rad Laboratories) with an initial hold step $\left(95^{\circ} \mathrm{C}\right.$ for $\left.10 \mathrm{~min}\right)$, thirty-five cycles of a three-step PCR $\left(94^{\circ} \mathrm{C}\right.$ for $30 \mathrm{~s}, 55^{\circ} \mathrm{C}$ for $30 \mathrm{~s}, 72^{\circ} \mathrm{C}$ for $1 \mathrm{~min}$ ) and a final hold step $\left(72^{\circ} \mathrm{C}\right.$ for $\left.10 \mathrm{~min}\right)$. The purity of PCR products was verified by gel electrophoresis. PCR products $(20 \mu \mathrm{l})$ were digested with $9 \mathrm{U}$ of either Dde $\mathrm{I}^{(24)}$ (New England Biolabs), Alu I or $R s a \mathrm{I}^{(25)}$ (Fermentas) at $37^{\circ} \mathrm{C}$ for $1.5 \mathrm{~h}$ and subsequently inactivated by an incubation at $65^{\circ} \mathrm{C}$ for $20 \mathrm{~min}$. The length of the DNA fragments was determined with a chip-based (HT DNA 5k LabChip Kit; Caliper Life Sciences, Mainz, Germany) microfluidic capillary electrophoresis (LabChip GX; Caliper) according to the manufacturer's instructions. Cluster analyses were performed using BioNumerics software (Applied Maths, Sint-Martens-Latem, Belgium). Pearson's similarity coefficient analysis and the unweighted pair-group methods with arithmetic means were used to establish the type of dendrogram. 


\section{Statistical analyses}

All results are given as means with their standard errors. ANOVA (one-way ANOVA) with the consequent post hoc test of Tukey was applied for the determination of significance levels (Graph Pad Prism Version 4.00; GraphPad Software, San Diego, CA, USA). Value distributions within the single groups were checked for homogeneity of variances (Bartlett's test) to meet the requirements for applicability of ANOVA. Post hoc testing was done when the means were significantly different in ANOVA. The Mann-Whitney $U$ test was used where appropriate to determine differences between two groups. Differences were considered as significant if the $P$ value was $<0.05$.

\section{Results}

In previous studies, we found that chronic intake of $\mathrm{F}$ for 8 weeks resulted in a marked lipid accumulation in the liver $^{(20)}$. The increased lipid accumulation was also associated with significantly higher plasma levels of the insulin resistance marker retinol binding protein 4 (about 1.5-fold, $P<0.05$ ). Similar effects of the fructose feeding were not found in mice concomitantly treated with antibiotics.

\section{Effect of chronic fructose intake on protein levels of occludin in the small and large intestine}

Protein levels of the tight junction protein occludin were significantly lower in the duodenum of mice exposed chronically to fructose (Fig. 1). Interestingly, a similar effect on occludin protein levels was not found in the ileum or colon of fructose-fed animals (Fig. 1). However, when comparing water controls, protein levels of occludin were found to be markedly lower in these regions of the gastrointestinal tract in comparison to the duodenum (Fig. 1).

\section{Effect of fructose intake on intestinal microbiota in the duodenum, ileum and colon}

As the results of others suggest that patients with NAFLD more frequently have bacterial overgrowth than controls ${ }^{(26)}$, we determined if the chronic intake of fructose was associated with alterations of the microbiota in the duodenum, ileum and colon of mice using DNA-fingerprinting. Results are summarised in Figs. 2-4. As was to be expected in the duodenum, concentration of bacterial $16 \mathrm{~S}$ rDNA was low regardless of the feeding regimen. Nevertheless, when analysing digested $16 \mathrm{~S}$ rDNA samples using microfluidic capillary electrophoresis, a specific band pattern was found in five out of six fructosefed mice and four out of six water-fed controls. However, cluster analysis of bands revealed no group-specific patterns between groups (Fig. 2). In contrast, in samples obtained from the ileum, a similarity regarding band patterns was found between most fructose-fed animals (Fig. 3). Furthermore, DNA band patterns of fructose-fed mice differed markedly from that of water-fed controls in the ileum. Interestingly, a similar effect was not found when samples obtained from the colon were analysed (Fig. 4). The intestinal microbiota was not analysed in mice that had been treated with non-absorbable antibiotics to 'sterilise' the gut, as the number of colony-forming units in faeces obtained from these animals was markedly lower than in water controls (about $-90 \%$; data not shown); and we therefore did not

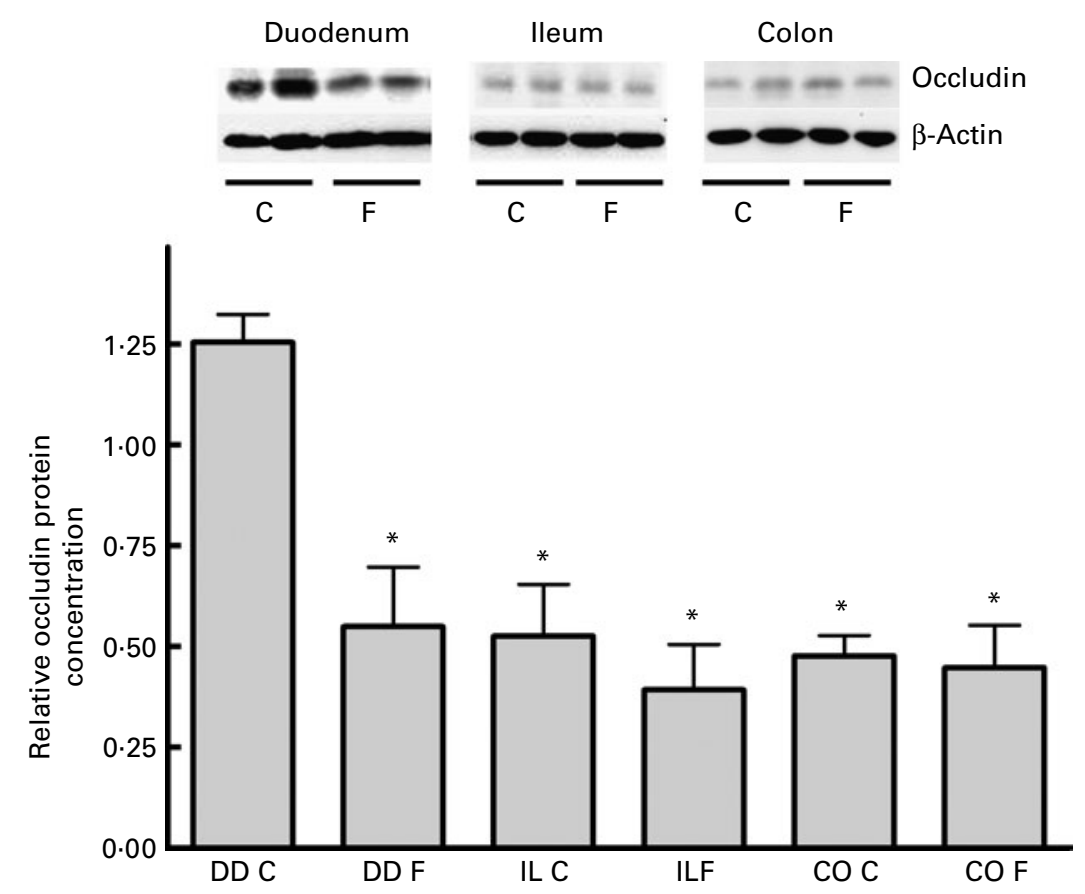

Fig. 1. Effect of chronic consumption of $30 \%$ fructose solution (F) on occludin protein concentrations in the duodenum (DD), ileum (IL) and colon (CO). Representative pictures of occludin Western blots as well as quantitative analysis of blots. Values are means, with their standard errors represented by vertical bars ( $n$ 5-6). C, control animals. * Mean value was significantly different from that of DD $\mathrm{C}(P<0.05)$. 
(a)

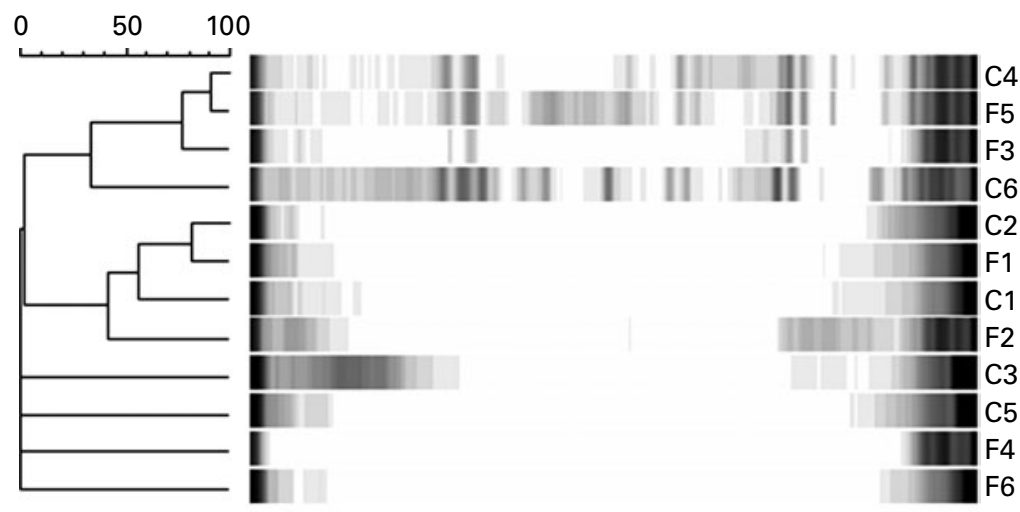

(b)

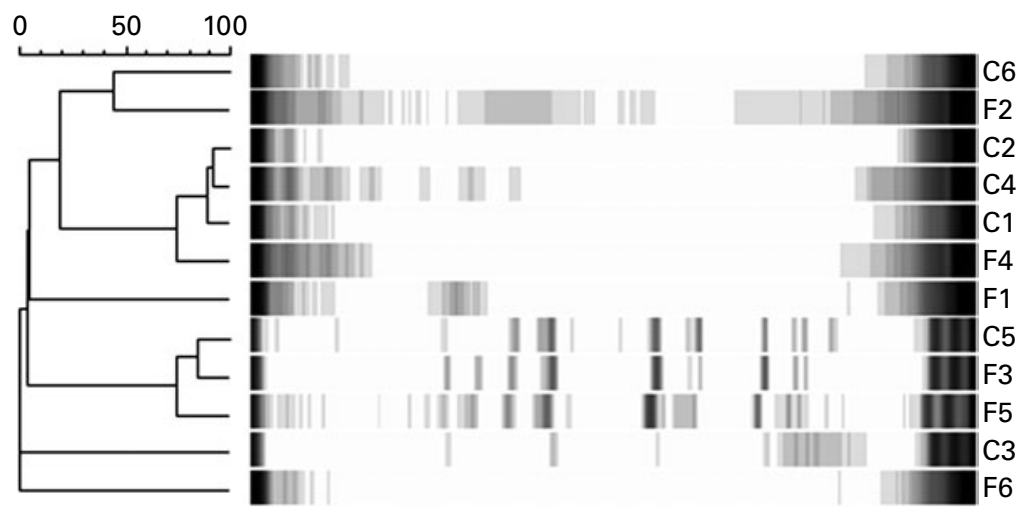

(c)

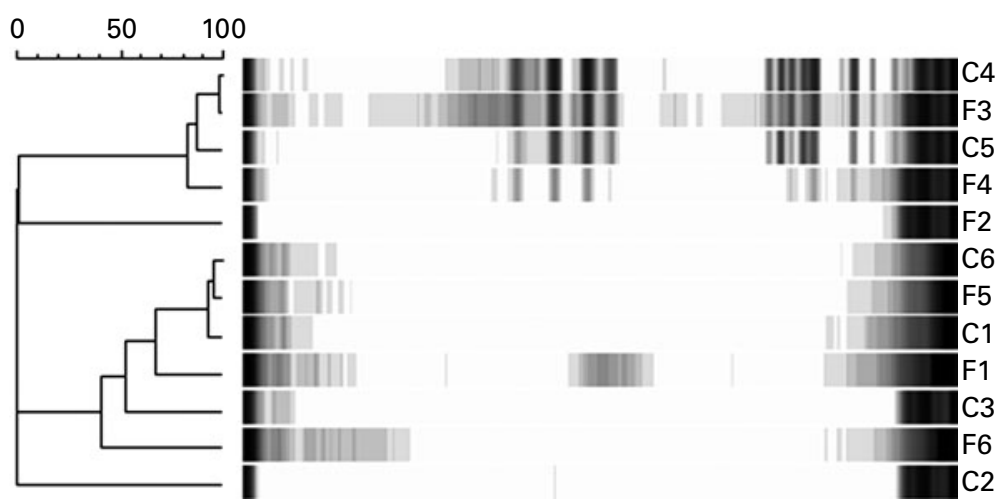

Fig. 2. Effect of chronic consumption of $30 \%$ fructose solution $(F)$ on microbiota in the duodenum. Bacterial $16 \mathrm{~S}$ ribosomal DNA was isolated from duodenal tissue and was digested with different restriction enzymes (a) Alu I, (b) Dde I and (c) Rsa I. The length of DNA fragments was determined with chip-based microfluidic capillary electrophoresis. Pearson's similarity coefficient analysis and the unweighted pair-group methods with arithmetic means were used to establish the type of dendrogram. C, control animals.

expect any detectable band patterns of restricted bacterial $16 \mathrm{~S}$ rDNA in the duodenum or ileum.

Effect of the treatment with antibiotics on the expression of toll-like receptor, myeloid differentiation factor $88, \mathrm{~F} 4 / 80$ and macrophage number in the liver of fructose-fed mice

To clarify if the increased accumulation of fat in the liver ${ }^{(20)}$ was also associated with increases in the expression of different TLR in the liver, we determined expression levels of TLR1-9 in whole liver homogenate of those mice that were used in our previous study ${ }^{(20)}$ (Fig. 5). Indeed, not only expression of the bacterial endotoxin receptor TLR4 but also expression levels of TLR 1, 2, 3, 6, 7 and 8 were significantly induced by about 2-4-fold in livers of mice chronically exposed to the $\mathrm{F}$ in comparison to water controls. Similar changes were not found for TLR 5 and 9 mRNA expression. The increased expression levels of TLR (Fig. 5) and MyD88 (Fig. 6(a)) found in livers of fructose-fed mice were associated with a markedly increased mRNA expression of the macrophage marker F4/80 (Fig. 7(c)) and an increased number of macrophages as determined by staining of $\mathrm{F} 4 / 80$ (Fig. 7 (a) and (b)). Interestingly, in livers of fructose-fed mice concomitantly 
(a)

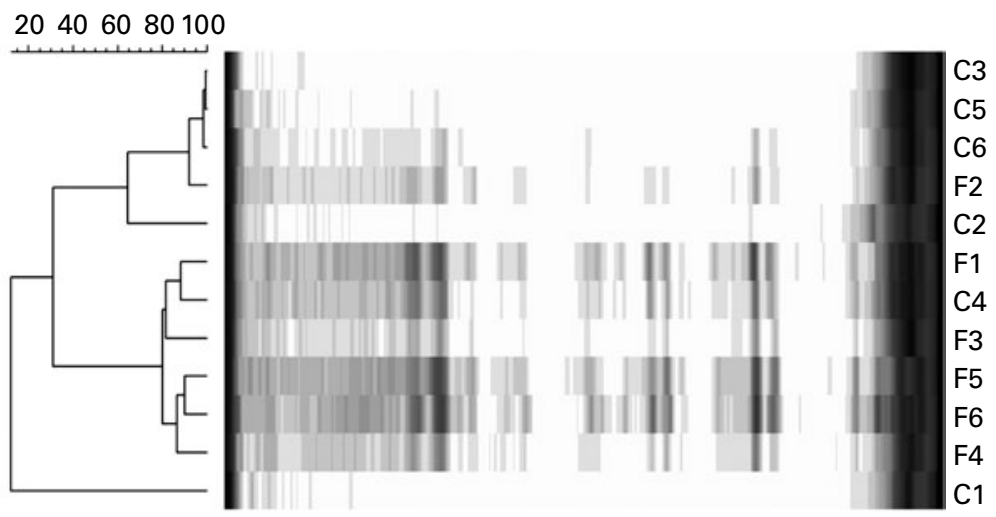

(b)
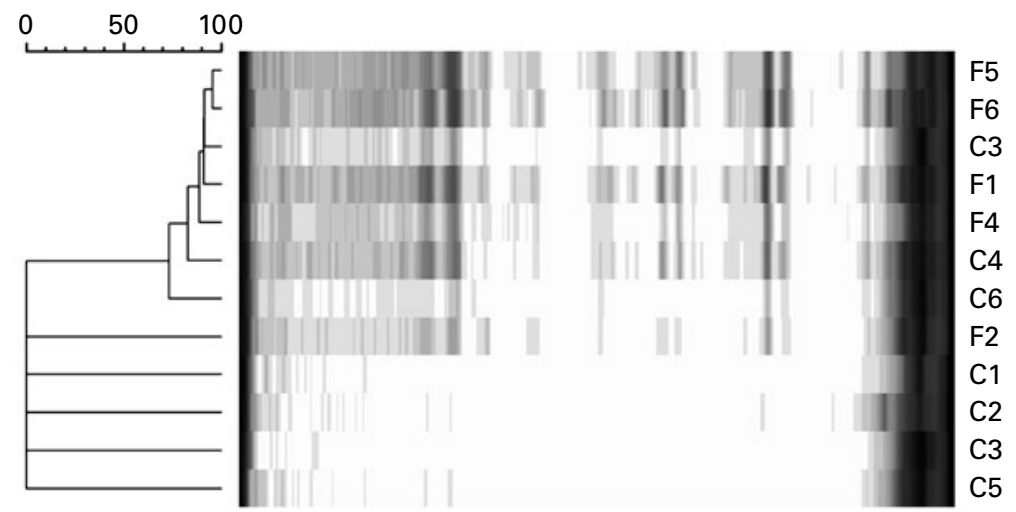

(c)

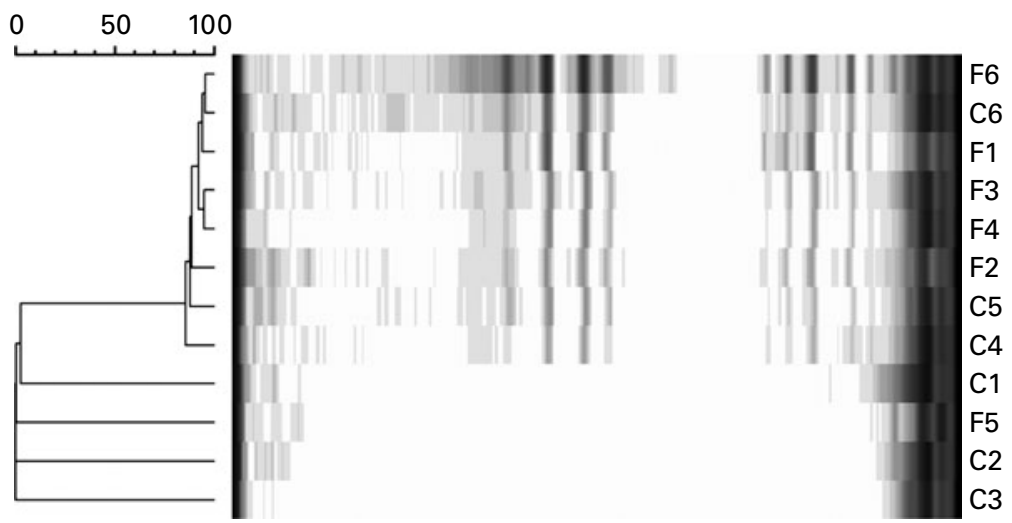

Fig. 3. Effect of chronic consumption of $30 \%$ fructose solution $(F)$ on microbiota in the ileum. Bacterial $16 \mathrm{~S}$ ribosomal DNA was isolated from ileal tissue and was digested with different restriction enzymes (a) Alu I, (b) Dde I and (c) Rsa I. The length of DNA fragments was determined with chip-based microfluidic capillary electrophoresis. Pearson's similarity coefficient analysis and the unweighted pair-group methods with arithmetic means were used to establish the type of dendrogram. C, control animals.

treated with the non-resorbable antibiotics neomycin and polymyxin $\mathrm{B}$, which both destroy Gram-negative bacteria as also Gram-positive bacteria, not only hepatic fat accumulation was markedly suppressed ${ }^{(20)}$ but also expression of the different TLR (Fig. 5), their adaptor protein MyD88 (Fig. 6(a)), and F4/80 (Fig. 7(c)) and the numbers of F4/80 positive cells were reduced almost to the level of water controls (Fig. 7(a) and (b)).
Effect of the antibiotic treatment on TNF $\alpha$ and inducible NO synthase mRNA in the liver of fructose-fed mice

In the present study, we found in the same mice that were used in our previous study ${ }^{(20)}$ that the protective effects of the treatment with antibiotics were associated with a significant attenuation of the induction of TNF $\alpha$ and iNOS mRNA expression found in the liver after chronic fructose exposure (Fig. 6(b) and (c)). 
(a)

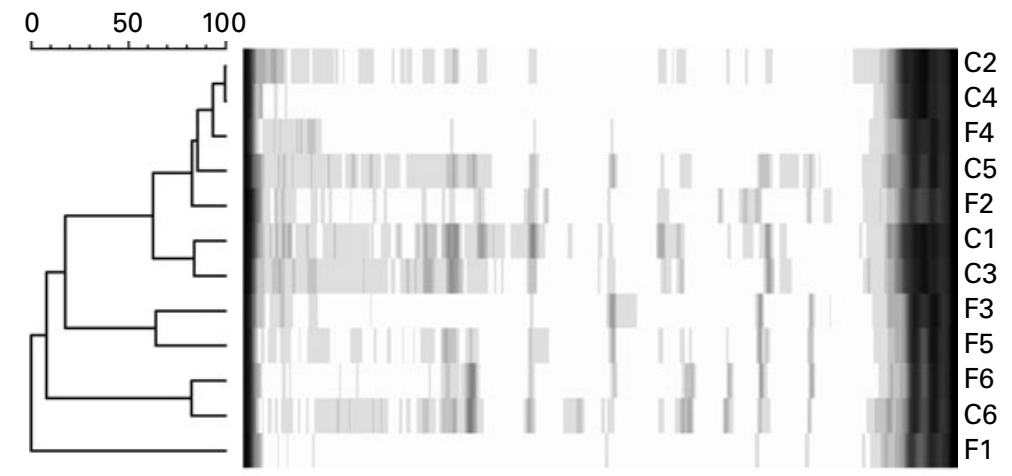

(b)
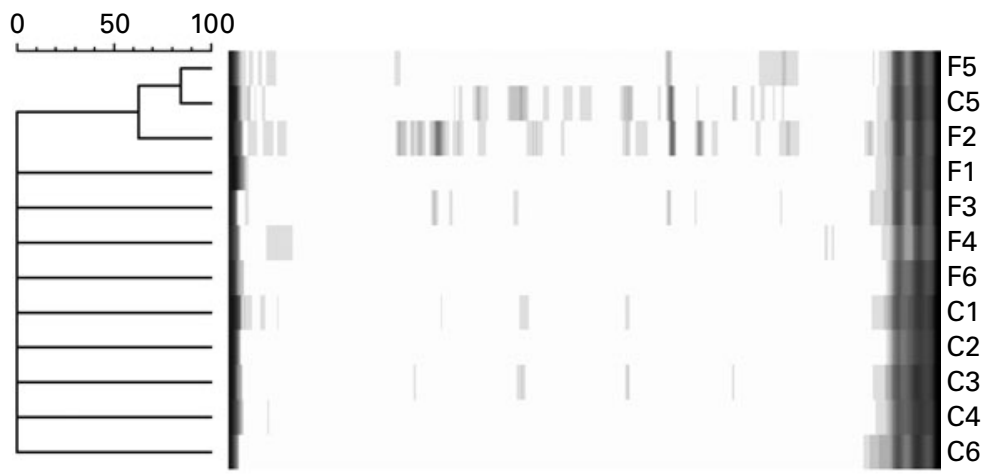

(c)

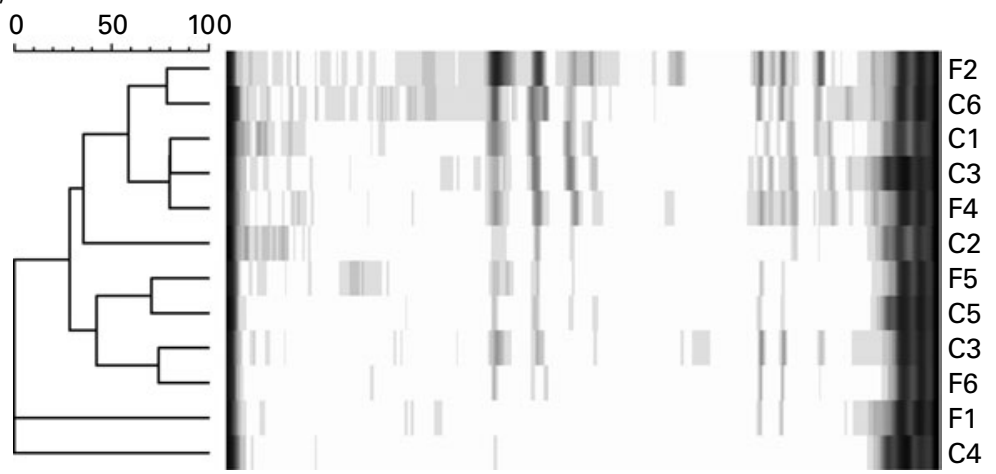

Fig. 4. Effect of chronic consumption of $30 \%$ fructose solution $(F)$ on microbiota in the colon. Bacterial 165 ribosomal DNA was isolated from colonic tissue and was digested with different restriction enzymes (a) Alu I, (b) Dde I and (c) Rsa I. The length of DNA fragments was determined with chip-based microfluidic capillary electrophoresis. Pearson's similarity coefficient analysis and the unweighted pair-group methods with arithmetic means were used to establish the type of dendrogram. C, control animals.

\section{Discussion}

Results of several studies in human subjects and animals suggest that an increased dietary intake of fructose may be a risk factor in the development of NAFLD ${ }^{(27-29)}$. Indeed, a recent study in US patients suggests that an increased consumption of fructose may even increase the risk of developing fibrosis $^{(17)}$. Results of a small pilot study performed in patients with non-alcoholic steatohepatitis suggest that a reduction of fructose intake may exert beneficial effects on the progression of this disease in humans ${ }^{(30)}$. Similar to what was found for the development of alcoholic liver disease (for an overview, see Arteel $^{(31)}$ ), results of our own group obtained in animal studies suggest that an increased translocation of bacterial endotoxins subsequently leading to a TLR-4-dependent activation of hepatic Kupffer cells may contribute significantly to the development of fructose-induced hepatic steatosis in mice $20,23,22)$ In animal models of alcoholic liver disease, it has been shown that other TLR besides TLR 4 in the liver may also be involved in the development of steatosis ${ }^{(32)}$. Whether other TLR besides TLR 4 in the liver are also affected by the chronic intake of fructose and whether alterations of the microbiota in the intestine are associated with the onset of fructose-induced steatosis has not yet been clarified. In the present study, by feeding mice with a moderately fructose-enhanced diet (e.g. $30 \%$ fructose in drinking solutions) and concomitantly treating them with non-resorbable antibiotics, we further tested the hypothesis that the liver is also sensitised by other microbial 

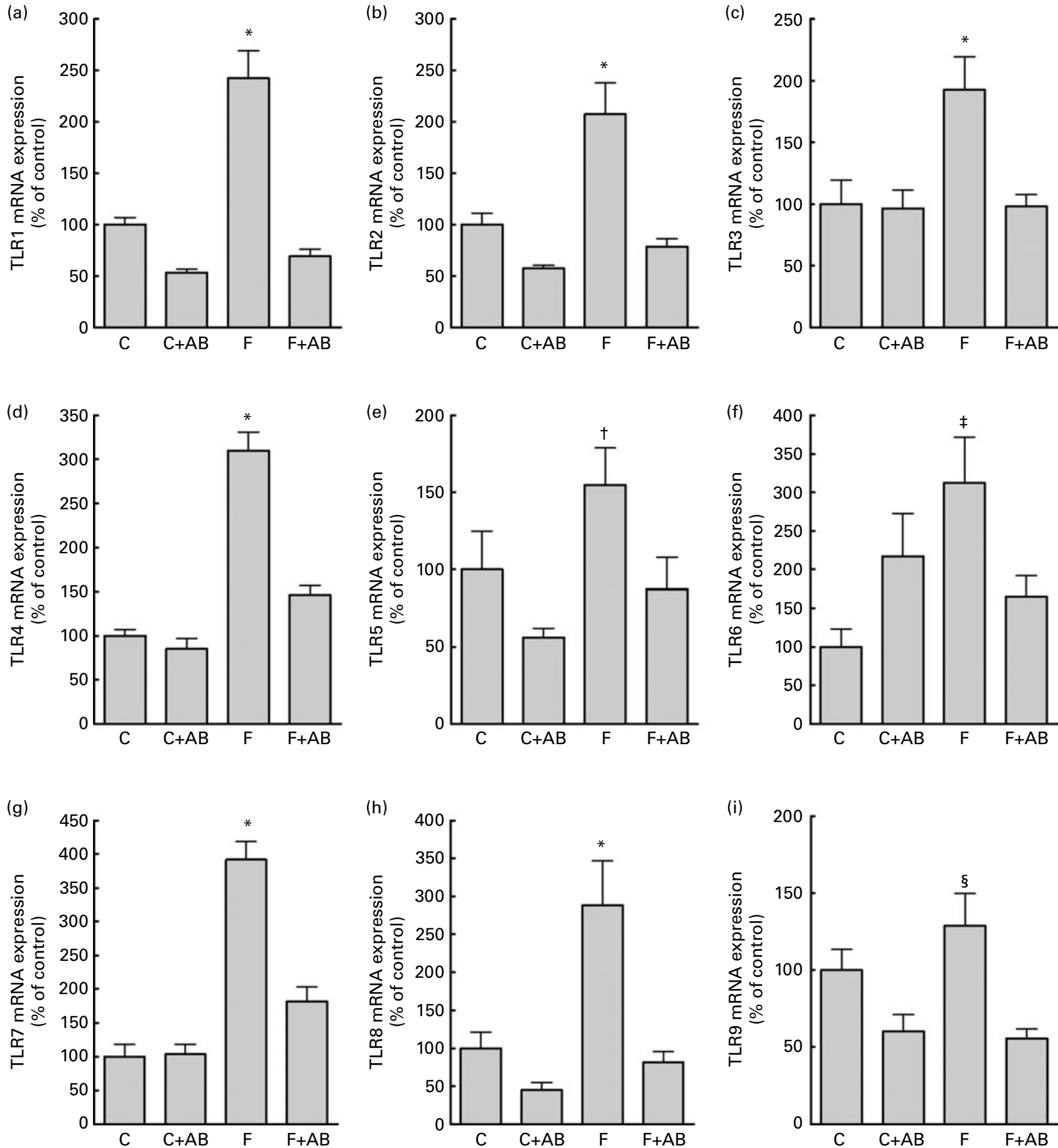

Fig. 5. Effect of chronic consumption of $30 \%$ fructose solution $(F)$ and treatment with antibiotics on hepatic mRNA expression of (a-i) toll-like receptors (TLR) $1-9$. TLR1-9 mRNA expression was determined by real-time RT-PCR. TLR1-9 expression levels were normalised to $\beta$-actin expression. Values are means, with their standard errors represented by vertical bars $(n=5-7)$ and are normalised to percentage of control. * Mean value was significantly different from those of control animals, control animals treated with antibiotics and mice fed $\mathrm{F}$ and treated with antibiotics $(P<0.05)$. $†$ Mean value was significantly different from those of control animals treated with antibiotics $(P<0.05)$. $¥$ Mean value was significantly different from that of control animals $(P<0.05)$. $\S$ Mean value was significantly different from those of control animals treated with antibiotics and mice fed $\mathrm{F}$ and treated with antibiotics $(P<0.05)$. $\mathrm{C}$, water; $\mathrm{AB}$, treatment with antibiotics (polymyxin B and neomycin).

components besides bacterial endotoxin derived from Gram-negative bacteria during the onset of fructose-induced NAFLD. We further investigated if the onset of fructoseinduced steatosis is associated with alterations of the microbiota in the intestine. Although it should be emphasised that a $\mathrm{F}$ by no means mimics beverages consumed by humans (e.g. soft drinks: about 9-11\% sugar from sucrose or high-fructose corn syrup, apple juice: about $11 \%$ sugar as 

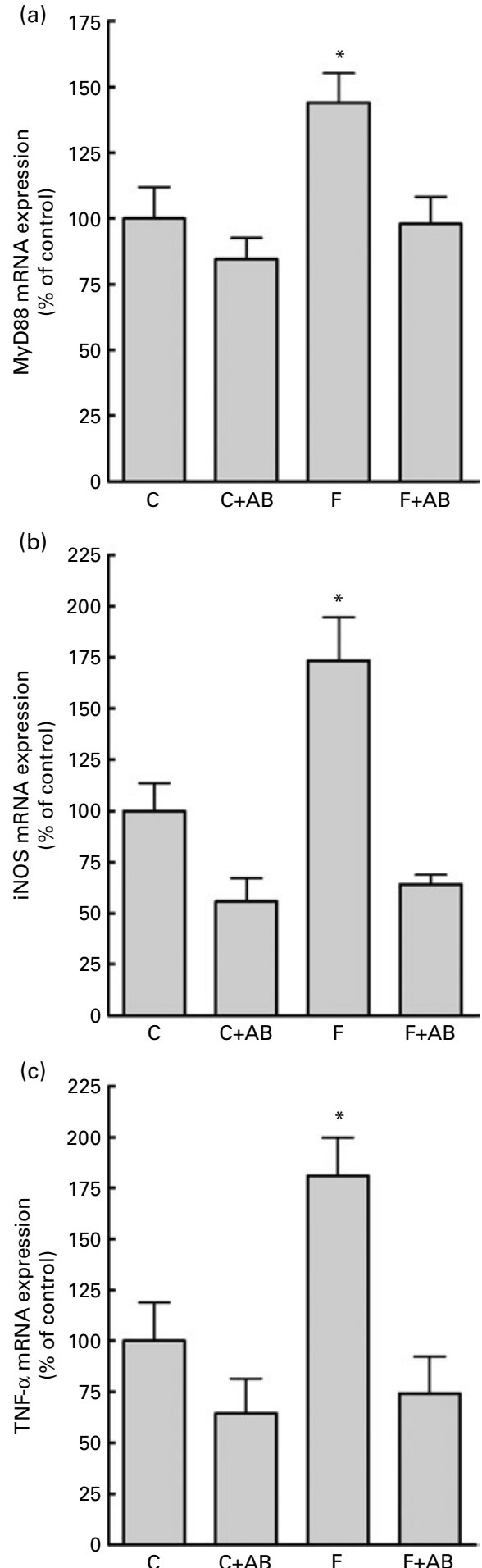

Fig. 6. Effect of chronic consumption of $30 \%$ fructose solution $(F)$ and treatment with antibiotics on hepatic mRNA expression of (a) myeloid differentiation factor 88 (MyD88), (b) inducible NO synthase (iNOS) and (c) TNF $\alpha$. MyD88, iNOS and TNF $\alpha$ mRNA expression was determined by realtime RT-PCR. MyD88, iNOS and TNF $\alpha$ expression levels were normalised to $\beta$-actin expression. Values are means, with their standard errors represented by vertical bars $(n=5-7)$ and are normalised to percentage of control. * Mean value was significantly different from those of control animals, control animals treated with antibiotics and mice fed $F$ and treated with antibiotics $(P<0.05)$. $\mathrm{C}$, water; $\mathrm{AB}$, treatment with antibiotics (polymyxin $\mathrm{B}$ and neomycin). free fructose), this model can serve to identify potential mechanisms involved in the onset of NAFLD and as a screening tool for new therapies. In mice chronically exposed to fructose, mRNA expression of TLR 1, 2, 3, 4, 6, 7 and 8 in the liver was markedly higher than in controls. Interestingly, a similar effect was not found for TLR 5 and 9. The lack of induction of these two TLR may have resulted from a lack of a sufficient concentration of inducers (e.g. flagellin, unmethylated CpG motifs). However, the mechanisms involved in the lack of induction of these TLR need to be addressed in future studies. Furthermore, expression of the TLR-adaptor protein MyD88, which has been shown before to be involved in the rapid activation of $\mathrm{NF \kappa B}$ and the subsequent increase of TNF $\alpha$ expression ${ }^{(33,34)}$ upon activation of TLR, was markedly higher in fructose-fed mice. In line with these findings, expression of iNOS and TNF $\alpha$ was also induced in livers of mice fed chronically with fructose in comparison to water controls. However, the degree of induction found for the latter was markedly higher than that found for MyD88 mRNA expression. This apparent discrepancy might have resulted from differences in the efficacy of the PCR-assay or that MyD88 signalling is not only regulated by its expression but also by its protein/phosphorylation status. The markedly higher levels of TLR as also iNOS and TNF $\alpha$ mRNA expression were associated with an increased number of F4/80 positive cells, indicating that the number of macrophages, be it Kupffer cells or infiltrating macrophages, was increased in mice fed fructose. This is in line with the findings of Kohli et al. ${ }^{(35)}$, who found more macrophages in the livers of mice fed a high-fat and high-fructose diet in comparison to high-fat-fed animals. It was further recently reported by Ueberham et $a .^{(36)}$ that mice fed a choline-deficient, ethioninesupplemented diet, which was shown before by other groups to induce NAFLD ${ }^{(37)}$, display an increased number of F4/80 positive cells in the liver. The results of this study further suggest that these F4/80 positive cells were Kupffer cells rather than infiltrating macrophages. However, whether in the present study, the enhanced number of F4/80 positive cells are infiltrating macrophages or proliferated Kupffer cells remains to be determined. Interestingly, in fructose-fed mice concomitantly treated with antibiotics, not only hepatic lipid accumulation was reduced ${ }^{(20)}$, but also expression of all TLR studied as well as MyD88, iNOS and TNF $\alpha$ were at the levels of controls. In addition, the numbers of $\mathrm{F} 4 / 80$ positive cells were at the level of controls. Taken together, these data support the hypothesis that (1) an increased intestinal translocation of bacterial endotoxin derived from Gram-negative bacteria and other microbial components and (2) an increased number of F4/80 positive cells as well as higher concentration of TLR and induction of dependent pathways (e.g. MyD88 and iNOS) may be involved in the onset of fructose-induced NAFLD. Our findings by no means precluded that fructose may also lead to hepatic steatosis through mechanisms depending on its insulin-independent metabolism (e.g. through bypassing the main rate-limiting step in glycolysis (for an overview, also see Basciano et al. $^{(38)}$ )) in the liver; rather our data suggest that chronic intake of certain sugars (e.g. fructose) may at least in part contribute to the 


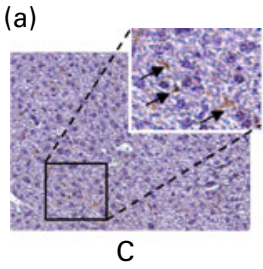

(b)

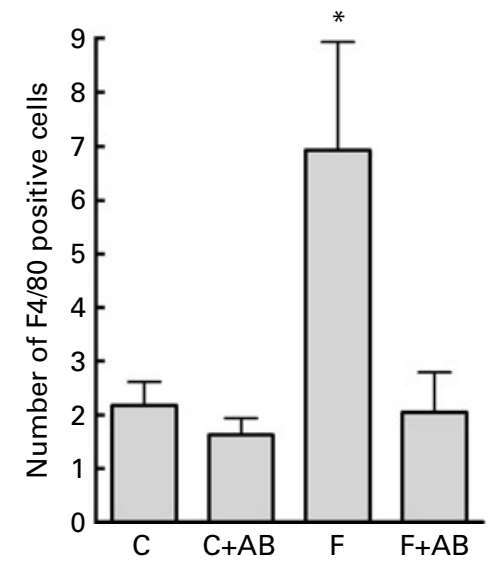

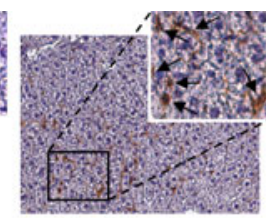

$\mathrm{F}$

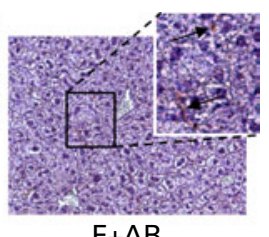

$\mathrm{F}+\mathrm{AB}$

(c)

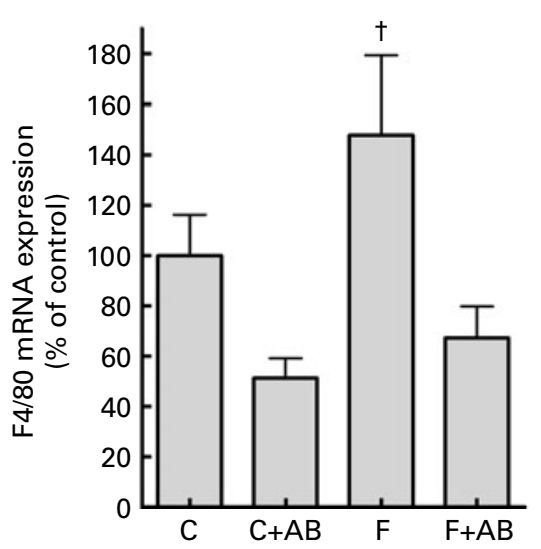

Fig. 7. Effect of chronic consumption of $30 \%$ fructose solution (F) on F4/80 positive cells in the liver. (a) Representative photomicrographs (200 $\times$ ) of $F 4 / 80$ positive cells (brown stained cells marked with black arrows indicate F4/80 staining). (b) Quantification of F4/80 staining. Data from eight fields (630 $\times$ ) of each tissue section ( $n=6-7$ per group) were used to determine means. (c) F4/80 mRNA expression was determined by real-time RT-PCR and was normalised to $\beta$-actin expression $(n=6-7)$. Values are means, with their standard errors represented by vertical bars. * Mean value was significantly different from those of control animals, control animals treated with antibiotics and mice fed $\mathrm{F}$ and treated with antibiotics $(P<0.05)$. $†$ Mean value was significantly different from those of control animals treated with antibiotics and mice fed $\mathrm{F}$ and treated with antibiotics $(P<0.05)$. $\mathrm{C}$, water; $\mathrm{AB}$, treatment with antibiotics (polymyxin $\mathrm{B}$ and neomycin).

development of the early phase of NAFLD through mechanisms involving an increased translocation of microbial components of intestinal origin.

\section{How does chronic intake of fructose lead to an increased translocation of intestinal microbial components?}

Results of animal studies of our own group ${ }^{(23)}$ and those of others groups ${ }^{(39,40)}$ suggest that the increased translocation of bacterial endotoxin and activation of TLR-4-dependent pathways in the liver found in mice displaying hepatic steatosis or steatohepatitis are associated with an increased intestinal permeability and a marked loss of tight junction proteins in the intestine. Furthermore, it has recently been shown that patients with NAFLD have an increased intestinal permeability and that these alterations are not only associated with a higher prevalence of small intestine bacterial overgrowth but also lower levels of the tight junction protein zonula occludens 1 in the duodenum ${ }^{(41)}$. In the present study, protein levels of the tight junction protein occludin were found to be markedly lower in the duodenum of mice chronically exposed to fructose in comparison to water controls, whereas similar changes were not found in lower parts of the small intestine (e.g. ileum) or colon. Furthermore, it has been suggested by studies in human subjects that NAFLD is associated at least in some patients with small intestine bacterial overgrowth ${ }^{(41,26)}$. In line with these findings, changes in the composition of the bacterial flora have been discussed to be associated not only with the development of obesity (for an overview, see
Cani \& Delzenne ${ }^{(42)}$ ), but also the onset of fat-induced NAFLD in mice ${ }^{(40)}$. In the present study, no systematic differences of DNA band patterns were found between controls or fructose-fed animals in the duodenum or colon. However, band patterns of $16 \mathrm{~s}$ rDNA samples obtained from the ileum of fructose-fed animals were markedly different from those of water controls. Taken together, these data suggest that chronic intake of fructose is associated with a marked reduction of the protein concentration of the tight junction protein occludin in the duodenum but no changes in the composition of the microbiota in this part of the intestine. These findings are also supported by earlier findings of our group in which we showed that both chronic intake of glucose and fructose can lead to increased portal endotoxin levels and subsequently hepatic steatosis when the concentration of the tight junction protein occludin in the duodenum is decreased $^{(23)}$. These results also suggest that certain components of the diet (e.g. fructose) may affect tight junction proteins in the intestine directly, subsequently leading to an increased permeability. However, mechanisms involved in the nutrition-dependent regulation of tight junction proteins remain to be determined.

\section{Conclusion}

Taken together, our data further support the hypothesis that a diet rich in fructose may at least in part add to the onset of NAFLD through mechanisms involving an increased translocation of intestinal microbial components, altered 
concentration of TLR and activation of TLR-dependent signalling pathways. Our data further suggest that fructose may alter intestinal permeability through altering tight junction proteins (e.g. occludin) in the duodenum directly rather than altering intestinal microbiota composition. However, additional studies will be necessary to further explore the underlying mechanism and possible resulting therapeutic and prevention strategies.

\section{Acknowledgements}

The present project has been funded by a grant of the Federal Ministry of Education and Research (FKZ: 0315084) (to I. B.). This work was also supported by the 'Kompetenznetz Adipositas (Competence Network of Obesity)' funded by the Federal Ministry of Education and Research (FKZ: 01GI0843) (to I. B. and S. C. B.). I. B. designed the research; S. W., A. S., G. K., V. V. and C. S. conducted the research; S. W., A. S., G. K., V. V. and C. S. analysed the data; S. W. and I. B. wrote the paper; S. C. B. advised the work; and I. B. had primary responsibility for the final content. None of the authors has any conflict of interest. The authors thank Caliper Life Sciences, Mainz, Germany, for their technical support.

\section{References}

1. Bedogni G, Miglioli L, Masutti F, et al. (2005) Prevalence of and risk factors for nonalcoholic fatty liver disease: the Dionysos nutrition and liver study. Hepatology 42, 44-52.

2. Yang SQ, Lin HZ, Mandal AK, et al. (2001) Disrupted signaling and inhibited regeneration in obese mice with fatty livers: implications for nonalcoholic fatty liver disease pathophysiology. Hepatology 34, 694-706.

3. Adams LA, Lymp JF, St Sauver J, et al. (2005) The natural history of nonalcoholic fatty liver disease: a populationbased cohort study. Gastroenterology 129, 113-121.

4. Clark JM, Brancati FL \& Diehl AM (2003) The prevalence and etiology of elevated aminotransferase levels in the United States. Am J Gastroenterol 98, 960-967.

5. Clark JM (2006) The epidemiology of nonalcoholic fatty liver disease in adults. J Clin Gastroenterol 40, Suppl. 1, S5-S10.

6. Mencin A, Kluwe J \& Schwabe RF (2009) Toll-like receptors as targets in chronic liver diseases. Gut 58, 704-720.

7. Akira S, Takeda K \& Kaisho T (2001) Toll-like receptors: critical proteins linking innate and acquired immunity. Nat Immunol 2, 675-680.

8. Takeda K \& Akira S (2001) Roles of toll-like receptors in innate immune responses. Genes Cells 6, 733-742.

9. Alexopoulou L, Holt AC, Medzhitov R, et al. (2001) Recognition of double-stranded RNA and activation of NF-kappaB by toll-like receptor 3. Nature $\mathbf{4 1 3}, 732-738$.

10. Hayashi F, Smith KD, Ozinsky A, et al. (2001) The innate immune response to bacterial flagellin is mediated by tolllike receptor 5. Nature 410, 1099-1103.

11. Poltorak A, He X, Smirnova I, et al. (1998) Defective LPS signaling in $\mathrm{C} 3 \mathrm{H} / \mathrm{HeJ}$ and $\mathrm{C} 57 \mathrm{BL} / 10 \mathrm{ScCr}$ mice: mutations in Tlr4 gene. Science 282, 2085-2088.

12. Heil F, Hemmi H, Hochrein H, et al. (2004) Species-specific recognition of single-stranded RNA via toll-like receptor 7 and 8. Science 303, 1526-1529.

13. Hemmi H, Takeuchi O, Kawai T, et al. (2000) A toll-like receptor recognizes bacterial DNA. Nature 408, 740-745.
14. Nagata K, Suzuki H \& Sakaguchi S (2007) Common pathogenic mechanism in development progression of liver injury caused by non-alcoholic or alcoholic steatohepatitis. J Toxicol Sci 32, 453-468.

15. Nagy LE (2003) Recent insights into the role of the innate immune system in the development of alcoholic liver disease. Exp Biol Med (Maywood) 228, 882-890.

16. Spruss A \& Bergheim I (2009) Dietary fructose and intestinal barrier: potential risk factor in the pathogenesis of nonalcoholic fatty liver disease. J Nutr Biochem 20, 657-662.

17. Abdelmalek MF, Suzuki A, Guy C, et al. (2010) Increased fructose consumption is associated with fibrosis severity in patients with nonalcoholic fatty liver disease. Hepatology 51, 1961-1971.

18. Ackerman Z, Oron-Herman M, Grozovski M, et al. (2005) Fructose-induced fatty liver disease: hepatic effects of blood pressure and plasma triglyceride reduction. Hypertension 45, 1012-1018.

19. Armutcu F, Coskun O, Gurel A, et al. (2005) Thymosin alpha 1 attenuates lipid peroxidation and improves fructoseinduced steatohepatitis in rats. Clin Biochem 38, 540-547.

20. Bergheim I, Weber S, Vos M, et al. (2008) Antibiotics protect against fructose-induced hepatic lipid accumulation in mice: role of endotoxin. J Hepatol 48, 983-992.

21. Faeh D, Minehira K, Schwarz JM, et al. (2005) Effect of fructose overfeeding and fish oil administration on hepatic de novo lipogenesis and insulin sensitivity in healthy men. Diabetes 54, 1907-1913.

22. Spruss A, Kanuri G, Wagnerberger S, et al. (2009) Toll-like receptor 4 is involved in the development of fructoseinduced hepatic steatosis in mice. Hepatology $\mathbf{5 0}$, 1094-1104.

23. Haub S, Kanuri G, Volynets V, et al. (2010) Serotonin reuptake transporter (SERT) plays a critical role in the onset of fructose-induced hepatic steatosis in mice. $A m \mathrm{~J}$ Physiol Gastrointest Liver Physiol 298, G335-G344.

24. Niscigorska-Olsen J, Wodecka B, Moranska I, et al. (2008) Genospecies of Borrelia burgdorferi sensu lato in patients with erythema migrans. Ann Agric Environ Med 15 $167-170$.

25. Christensen JE, Stencil JA \& Reed KD (2003) Rapid identification of bacteria from positive blood cultures by terminal restriction fragment length polymorphism profile analysis of the 16S rRNA gene. J Clin Microbiol 41, 3790-3800.

26. Wigg AJ, Roberts-Thomson IC, Dymock RB, et al. (2001) The role of small intestinal bacterial overgrowth, intestinal permeability, endotoxaemia, and tumour necrosis factor alpha in the pathogenesis of non-alcoholic steatohepatitis. Gut 48, 206-211.

27. Abid A, Taha O, Nseir W, et al. (2009) Soft drink consumption is associated with fatty liver disease independent of metabolic syndrome. J Hepatol 51, 918-924.

28. Ouyang X, Cirillo P, Sautin Y, et al. (2008) Fructose consumption as a risk factor for non-alcoholic fatty liver disease. J Hepatol 48, 993-999.

29. Zelber-Sagi S, Nitzan-Kaluski D, Goldsmith R, et al. (2007) Long term nutritional intake and the risk for non-alcoholic fatty liver disease (NAFLD): a population based study. J Hepatol 47, 711-717.

30. Assy N, Nasser G, Kamayse I, et al. (2008) Soft drink consumption linked with fatty liver in the absence of traditional risk factors. Can J Gastroenterol 22, 811-816.

31. Arteel GE (2003) Oxidants and antioxidants in alcoholinduced liver disease. Gastroenterology 124, 778-790. 
32. Gustot T, Lemmers A, Moreno C, et al. (2006) Differential liver sensitization to toll-like receptor pathways in mice with alcoholic fatty liver. Hepatology 43, 989-1000.

33. Velayudham A, Hritz I, Dolganiuc A, et al. (2006) Critical role of toll-like receptors and the common TLR adaptor, MyD88, in induction of granulomas and liver injury. $J$ Hepatol 45, 813-824.

34. Hosoi T, Yokoyama S, Matsuo S, et al. (2010) Myeloid differentiation factor 88 (MyD88)-deficiency increases risk of diabetes in mice. PLoS One 5, e12537.

35. Kohli R, Kirby M, Xanthakos SA, et al. (2010) High-fructose, medium chain trans fat diet induces liver fibrosis and elevates plasma coenzyme Q9 in a novel murine model of obesity and nonalcoholic steatohepatitis. Hepatology 52, 934-944.

36. Ueberham E, Bottger J, Ueberham U, et al. (2010) Response of sinusoidal mouse liver cells to choline-deficient ethioninesupplemented diet. Comp Hepatol 9, 8.

37. Tirosh O, Artan A, Haroni-Simon M, et al. (2010) Impaired liver glucose production in a murine model of steatosis and endotoxemia: protection by inducible nitric oxide synthase. Antioxid Redox Signal 13, 13-26.

38. Basciano H, Federico L \& Adeli K (2005) Fructose, insulin resistance, and metabolic dyslipidemia. Nutr Metab (Lond) 2, 5 .

39. Brun P, Castagliuolo I, Di Leo V, et al. (2007) Increased intestinal permeability in obese mice: new evidence in the pathogenesis of nonalcoholic steatohepatitis. Am J Physiol Gastrointest Liver Physiol 292, G518-G525.

40. Cani PD, Delzenne NM, Amar J, et al. (2008) Role of gut microflora in the development of obesity and insulin resistance following high-fat diet feeding. Pathol Biol (Paris) 56, 305-309.

41. Miele L, Valenza V, La TG, et al. (2009) Increased intestinal permeability and tight junction alterations in nonalcoholic fatty liver disease. Hepatology 49, 1877-1887.

42. Cani PD \& Delzenne NM (2007) Gut microflora as a target for energy and metabolic homeostasis. Curr Opin Clin Nutr Metab Care 10, 729-734. 